\title{
Estudo Histeroscópico e Anatomopatológico do Endométrio de Mulheres na Pós-menopausa com Câncer de Mama, Antes e Após o Uso de Tamoxifeno
}

Tese de Doutorado apresentada à Escola Paulista de Medicina - Universidade Federal de São Paulo, em 05/02/98.

Autor: Manoel Afonso Guimarães Gonçalves

Orientador: Prof. Dr. Wagner José Gonçalves

Objetivo: avaliar a influência do tamoxifeno no aspecto histeroscópico e histopatológico por meio da histeroscopia.

Método: estudaram-se, prospectivamente, 46 pacientes, das quais 20 utilizaram a droga por periodo médio de 12 meses. Efetuou-se, antes e após o tratamento pelo fármaco, a histeroscopia associada à biópsia endometrial.

Resultados: a taxa de endométrio ativo antes e após a hormonioterapia adjuvante com tamoxifeno foi a mesma, atingindo $10,0 \%$.
Conclusão: a hormonioterapia adjuvante com tamoxifeno não aumentou a taxa de atividade proliferativa endometrial em pacientes com câncer de mama na pós-menopausa. Observam-se numerosas vesículas disseminadas por toda a cavidade uterina e isso constituiu o aspecto histeroscópico mais usual, talvez devido à atrofia cística do endométrio.

Palavras-chave: Histroscopia. Endométrio. Mama: câncer.

Avaliação Simultânea dos Parâmetros FSH Basal e Idade Como Fator Prognóstico da Intensidade da Resposta à Hiperestimulação Ovariana Controlada num Programa de Fertilização In Vitro e Transferência de Embriōes

Dissertação apresentada à Faculdade de Medicina da Universidade de São Paulo para obtenção do título de Mestre em Medicina, Área de concentração: Obstetrícia e Ginecologia, em 8/11/97.

Autor: Artur Dzik

Orientador: Prof. Dr. Laudelino de Oliveira Ramos

A técnica de fertilização in vitro e transferência de embriões na terapêutica de casais inférteis surgiu há dezoito anos e hoje contabiliza mais de 300.000 nascimentos em cinqüenta países diferentes. Neste trabalho estudamos a avaliação simultânea dos parâmetros FSH basal e idade como fator prognóstico da taxa de cancelamento em 45 ciclos terapêuticos de FIVeTE. As pacientes foram submetidas à hiperestimulação ovariana controlada com Gonadotrofina da Mulher Menopausada sob bloqueio do eixo hipotálamo-hipófise-ovário prévio com Análogo Agonista do Hormônio Liberador das Gonadotrofinas. A média da faixa etária foi de 33,9 $\pm 4,3$ anos. A indicação da FIVeTE foi fator tubo peritoneal $(73,3 \%)$, endometriose pélvica $(8,9 \%)$, fator masculino $(11,1 \%)$, fator ovulatório $(4,5 \%)$ e idiopático $(2,2 \%)$. A taxa de cancelamento foi de $24,4 \%$. As variáveis FSH e idade apresentaram nível descritivo de 0,009 e 0,041 respectivamente no "screening" das pacientes Boas respondedoras e Más respondedoras. Propomos um modelo estatístico onde estas duas variáveis são utilizadas em conjunto. Nossos resultados sugerem que a variável idade sensibiliza a variável FSH basal e vice-versa como fator prognóstico da taxa de cancelamento da FIVeTE.

Palavras-chave: Infertilidade. FSH. Fertilização in vitro. Transferência de embriões. Técnicas de reprodução. 